J. Lake Sci. (湖泊科学), 2012, 24(6): 891-898

http: //www. jlakes.org. E-mail : jlakes@niglas.ac.cn

(C) 2012 by Journal of Lake Sciences

\title{
䱊湖表层沉积物中多环芳烃分布特征及来源”
}

\author{
宁 怡 ${ }^{1,2}$, 柯用春 ${ }^{3}$, 邓建 $才^{1 * *}$, 胡维平 ${ }^{1}$, 高俊峰 ${ }^{1}$, 赵振华 ${ }^{2}$ \\ (1: 中国科学院南京地理与湖泊研究所湖泊与环境国家重点实验室,南京 210008) \\ (2:河海大学水文水资源与水利工程科学国家重点实验室,南京 210098) \\ (3:三亚市南繁科学技术研究院,三亚 572000)
}

\begin{abstract}
摘 要: 于 2010 年, 采用野外采样调查、色谱分析与统计比较的方法, 研究巢湖表层沉积物中 27 个采样点中多环芳烃 (PAHs) 分布特征及污染来源. 结果表明: 巢湖表层沉积物中检测出的 14 种优控 PAHs 总浓度为 $116.0 \sim 2832.2 \mathrm{ng} / \mathrm{g}$ (DW), 平均值为 $898.9 \pm 791.0 \mathrm{ng} / \mathrm{g}(\mathrm{DW})$. 多环芳烃组成主要以 $5 \sim 6$ 环 $\mathrm{PAHs}$ 为主, 占总量的 $32 \% \sim 58 \%$. 沉积物中总 有机碳含量与 PAHs 总量呈现良好相关性. 利用葱/ (葱 + 菲) 与苯并 $[\mathrm{a}]$ 葱 / (苯并 $[\mathrm{a}]$ 葱 + 屈) 比值法对 PAHs 来源进行 解析得出, 巢湖表层沉积物中 PAHs 主要来源为燃烧源. 与国内其它水体 PAHs 含量对比表明, 巢湖沉积物中 PAHs 污染 处于中等水平. 生态风险评估得出南汁河表层沉积物中 PAHs 存在生态风险, 其它采样点表层沉积物中 PAHs 生态风险均 较低.
\end{abstract}

关键词: 巢湖; 多环芳烃; 表层沉积物; 来源

\section{Distribution and sources of polycyclic aromatic hydrocarbons (PAHs) in surface sediment in Lake Chaohu}

\author{
NING Yi ${ }^{1,2}$, KE Yongchun $^{3}$, DENG Jiancai ${ }^{1}$, HU Weiping ${ }^{1}$, GAO Junfeng ${ }^{1} \&$ ZHAO Zhenhua $^{2}$ \\ (1: State Key Laboratory of Lake Science and Environment, Nanjing Institute of Geography and Limnology, Chinese Academy \\ of Sciences, Nanjing 210008, P. R. China) \\ (2: State Key Laboratory of Hydrology Water Resources and Hydraulic Engineering, Hohai University, Nanjing 210098, P. R. \\ China) \\ (3: Sanya Science and Technology Academy for Crop Winter Multiplication, Sanya 572000, P. R. China)
}

\begin{abstract}
To clarify polycyclic aromatic hydrocarbons (PAHs) contamination characteristics in Lake Chaohu, 27 surface sediment samples from different locations in the lake were collected in 2010. Concentrations of 14 kinds of PAHs measured by HPLC were identified as priority pollutants by the US EPA. The total concentration of PAHs ranged from 116.0 to $2832.2 \mathrm{ng} / \mathrm{g}$ dry weight, with an average value of $898.9 \pm 791.0 \mathrm{ng} / \mathrm{g}$ dry weight. The profiles of PAHs showed that 5-and 6-ring PAHs were predominant, which accounted for $32 \%-58 \%$ of the total, respectively. A good correlation between TOC content and the total PAHs concentration was observed. Based on Anthracene/( Anthracene + Phenanthrene) and Benzo (a) anthracene/( Benzo ( a ) anthracene + Chrysene) ratios, PAHs originated largely from the high-temperature pyrolytic process. Risk assessment indicated that the sediment in Nanfei River was most likely to pose biological impairment, while low toxicological risk of PAHs was found in other sampling sites.
\end{abstract}

Keywords: Lake Chaohu; polycyclic aromatic hydrocarbons( $\mathrm{PAHs})$; surface sediment; source

多环芳烃 $(\mathrm{PAHs})$ 是一类由两个或两个以上苯环相连组成的有机化合物, 主要来源于有机物的不完全 燃烧和交通排放等 ${ }^{\left[{ }^{1]}\right.}$. PAHs 广泛分布于大气、土壤、水体、生物体等环境介质中,因其具有致癌性和致突变

* 国家自然科学基金项目 (40902052) 和国家水体污染控制与治理科技重大专项项目 (2008ZX07526-002-08) 联合资 助. 2011-11-14 收稿;2012-02-21 收修改稿. 宁怡,男,1986 年生, 硕士研究生;E-mail : ningyi@ gmx. com.

** 通信作者;E-mail:jcdeng@ niglas. ac. cn. 
性, 并在环境介质中持久存在, 且易于在生物体内富集而倍受关注. 美国环境保护局 (EPA) 将 16 种多环芳 烃列人优先控制污染物名单, 随后我国也将 7 种 PAHs 列人 “中国环境优先控制污染物” 的黑名单. 由于 $\mathrm{PAHs}$ 溶解度低、疏水性强, 进人水体后容易被颗粒物 (如生物碎屑和胶体) 吸附, 并随着重力沉降作用在沉 积物中积累 ${ }^{[2-4]}$. 然而蓄集于沉积物中的 PAHs 在再悬浮过程中会向水体释放, 通过食物链传递给人体, 对人 类生存和发展构成潜在危害 ${ }^{[5-6]}$. 因此, 研究沉积物中 PAHs 的组成、分布与来源对于评价其污染状况及其生 态风险具有重要意义.

目前, 我国在多环芳烃分布和来源方面开展的研究, 主要集中于江河 (口) $)^{[7-11]}$ 等水体, 但对湖泊沉积物 多环芳烃污染研究相对较少 ${ }^{[12-13]}$. 巢湖是安徽省主要的水源地, 也是重要的水上运输枢纽. 近年来, 随着周 边以及上游地区社会经济的快速发展, 人湖工业废水与生活污水不断增加 ${ }^{[14]}$; 湖区四周居民日常生活煤、柴 燃烧以及交通运输、旅游与渔船燃油排放的 PAHs 通过河流及大气干湿沉降进人巢湖沉积物中. 这些残留在 沉积物中的 PAHs 对水生生态系统甚至居民生活可能产生不利影响. 因此, 本文通过测定巢湖表层沉积物中 PAHs 含量, 分析其残留水平、组成与分布特征, 并探讨其可能来源与生态风险, 为巢湖不同环境介质中 PAHs 污染防治提供科学依据.

\section{1 研究区概况}

巢湖位于安徽省中部, 形态呈鸟巢状, 是我国第五大淡水湖, 东西长 $54.5 \mathrm{~km}$, 南北平均宽度 $15.1 \mathrm{~km}$, 平 均水深 $2.4 \mathrm{~m}$. 有杭埠河、丰乐河、派河、南淝河等人湖河流, 湖水经裕溪河人长江. 由于大量工业废水排人湖 体, 再加上近年来流域旅游事业高速发展, 给巢湖水生态环境造成了巨大的压力 ${ }^{[15]}$.

\section{2 样品采集与分析}

\section{1 样品采集}

2010 年 8 月, 借助全球卫星定位系统, 采用彼得逊采样器对巢湖表层沉积物进行采样. 共布设 27 个采 样点(图 1), 其中西湖区 13 个, 湖中区 6 个, 东湖区 8 个. 样品采集后, 运回实验室, 于 $-30^{\circ} \mathrm{C}$ 保存直至分析.

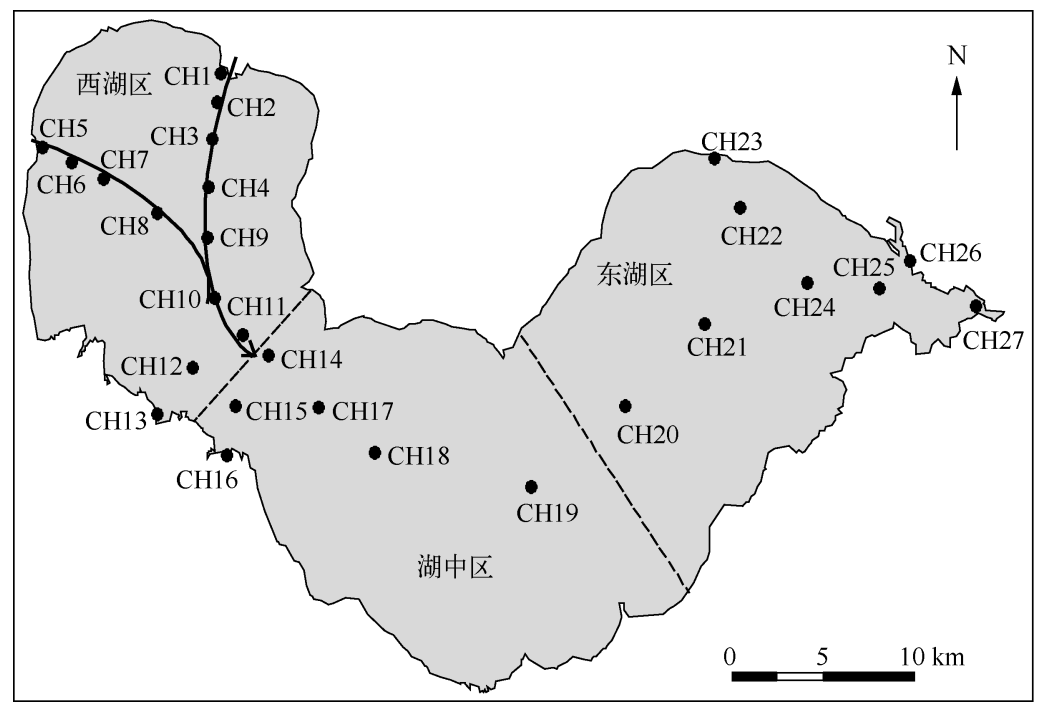

图 1 巢湖采样点分布

Fig. 1 Distribution of sampling sites in Lake Chaohu

\section{2 样品预处理}

沉积物样品经冷冻干燥研磨后过 100 目篮. 多环芳烃的提取采用加速溶剂萃取法 (ASE), 取 $10 \mathrm{~g}$ 样品 与硅藻土混合后填满萃取池. 以丙酮/正已烷混合液 (体积比为 $1: 1$ ) 作为提取剂, 同时加人铜粉脱硫. 萃取条 
件如下: 提取温度 $125^{\circ} \mathrm{C}$, 系统压强 $1500 \mathrm{psi}$, 静态萃取时间 $5 \mathrm{~min}$,加热时间 $7 \mathrm{~min}$. 氮吹时间 $60 \mathrm{~s}$, 循环 2 次. 收集萃取液, 萃取液经浓缩后置换为正已烷, 过自己填充的硅胶/氧化铝 (质量比为 4:1) 固相萃取柱. $15 \mathrm{ml}$ 正已烷/二氯甲烷 (体积比 7:3) 淋洗, 抽空. 收集淋洗液, 用高纯氮气将淋洗液吹至近干, 转换溶剂为乙腈, 定 容至 $1 \mathrm{ml}$ 待测.

\section{3 仪器条件}

美国 Agilent 公司高效液相色谱仪: Agilent Chemstation 工作站、Agilent 1200 系列紫外检测器、Agilent 1200 系列四元洜系统.

色谱柱: Agilent ZORBAX Eclipse XDB-C18 $(4.6 \mathrm{~mm} \times 250 \mathrm{~mm}, 5 \mu \mathrm{m})$. 检测器: 紫外检测器 $(254 \mathrm{~nm})$.

色谱条件:柱温: $25^{\circ} \mathrm{C}$. 流动相: 乙腈 - 水, 流速 $0.75 \mathrm{ml} / \mathrm{min}$, 线性梯度洗脱. $0 \sim 40 \mathrm{~min}$ 内, 乙腈从 $60 \%$ 变为 $100 \%$, 保持至 $50 \mathrm{~min}$, 然后在 $10 \mathrm{~min}$ 之内, 乙腈从 $100 \%$ 变回至 $60 \%$. 进样量: $6 \mu \mathrm{l}$. 紫外检测波长为 $254 \mathrm{~nm}$.

\section{4 质量控制与保证}

标样稀释为各种浓度样品以测定已建立方法的检出限, 本实验中多环芳烃的检测限为 $0.05 \sim$ $0.50 \mathrm{ng} / \mathrm{ml}$. 方法回收率在 $83 \% \sim 182 \%$, 满足痕量分析的要求. 方法回收率通过加人已知浓度标准品, 采用 同一实验方法测得,最后实验结果均经回收率校正.

\section{3 结果与讨论}

\section{1 PAHs 的空间分布及组成特征}

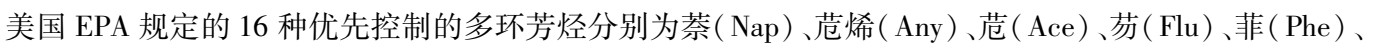

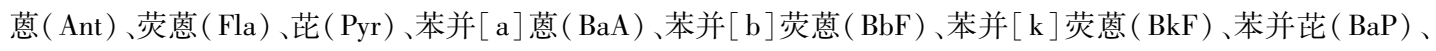
二苯并 $[\mathrm{a}, \mathrm{h}]$ 萝 $(\mathrm{DahA}) 、$ 、狮并 $[1,2,3-\mathrm{cd}]$ 芘 (IP)、屈 $(\mathrm{Chr})$ 和苯并 $[\mathrm{g}, \mathrm{h}, \mathrm{i}]$ 芘 (BghiP). 在巢湖 27 个采样点沉 积物样品中除苊烯及狮并 $[1,2,3$-cd $]$ 芘外, 其余 14 种均被检出. 巢湖表层沉积物中多环芳烃总浓度为 $116.0 \sim 2832.2 \mathrm{ng} / \mathrm{g}(\mathrm{DW})$, 平均值为 $898.9 \pm 791.0 \mathrm{ng} / \mathrm{g}(\mathrm{DW})$. 从分布特征来看, PAHs 含量最高点为 $\mathrm{CH} 1$, 达到 $2832.2 \mathrm{ng} / \mathrm{g}$ ( DW); $\mathrm{CH} 2$ 次之, 浓度为 $2662.5 \mathrm{ng} / \mathrm{g}$ ( DW), 这与其处于南淝河人湖口有关 (图 2a). 合肥 市区大量的工业废水、农业废水及生活污水经过排污管道直接排人南淝河, 经由南淝河进人湖体, 人类活动 影响较大 ${ }^{[16]}$. PAHs 含量最低点为 $\mathrm{CH} 12$, 浓度为 $116.0 \mathrm{ng} / \mathrm{g}(\mathrm{DW})$, 临近的 CH15 采样点浓度为 $166.9 \mathrm{ng} / \mathrm{g}$ (DW), 较 CH12 采样点略高. 这可能是由于其远离重污染区所致, 另外湖水的稀释作用也是重要原因, 采样 点 CH12 及 $\mathrm{CH} 15$ 处于丰乐-杭埠河至湖心的流向上, 而丰乐一杭埠河是注人巢湖水量最大的河流, 占总径流 量的 $65.1 \%$, 频繁的水体流动对污染物的稀释起了重要的作用. 巢湖不同湖区多环芳烃的污染情况也不尽 相同, 西湖区多环芳烃浓度最高, 东湖区次之, 湖中区最低, 其浓度均值分别为 $1193.9 \pm 976.0 、 888.6 \pm$ 430.0 和 $273.5 \pm 111.0 \mathrm{ng} / \mathrm{g}(\mathrm{DW})$ (图 $2 \mathrm{~b}$ ). 何开丽将巢湖分为东、西半湖, 发现西半湖 PAHs 污染程度远高 于东半湖 ${ }^{[17]}$, 与本研究结论基本一致.

通常多环芳烃来源较为复杂, 不同成因的多环芳烃结构和组分存在差异, 其环境行为也不同 ${ }^{[18]}$, 因此, 阐明环境中多环芳烃的组成特征, 可为了解其污染提供重要的信息. 巢湖表层沉积物中主要以 $5 \sim 6$ 环 PAHs 为主, 占总量的 $32 \% \sim 58 \% ; 2 \sim 3$ 环 PAHs 次之, 占总量的 14\% 51\%; 4 环 PAHs 最少, 占总量的 14\% $36 \%$ (图 3). 巢湖 27 个采样点表层沉积物中 Phe、Pyr、BbF、BaP 及 BghiP 浓度较高, 这 5 种组分含量总和占 巢湖表层沉积物 PAHs 总量的 $57 \%$. 邹爱红 ${ }^{[19]}$ 在研究巢湖水体有机物中也指出巢湖湖区污染与主要人湖河 流污染有关, 其研究得出巢湖水体中以 2 环 $\mathrm{PAHs}$ 为主, 这可能是由 PAHs 物理性质决定的, 随着环数的增 多, 分子量增加, 水溶性降低, 从而高环 PAHs 多环芳烃吸附在悬浮颗粒物上与外源输人共同进人沉积物中, 这也可能是本实验中的沉积物以 $5 \sim 6$ 环 PAHs 为主的原因.

\section{2 河口至湖心表层沉积物中 PAHs 分布特征}

由于流域地形、地貌条件的制约, 巢湖流域形成的高密度水系呈放射状汇人巢湖, 最终经裕溪河与长江 进行水体交换 ${ }^{[20]}$, 因此 PAHs 的空间分布除受到沿岸人类活动的影响外, 也与巢湖流域特殊的水动力条件 密切相关. 由南汁河河口向湖心延伸, 表层沉积物中 PAHs 浓度呈明显的下降趋势; 但是派河口向湖心方向 

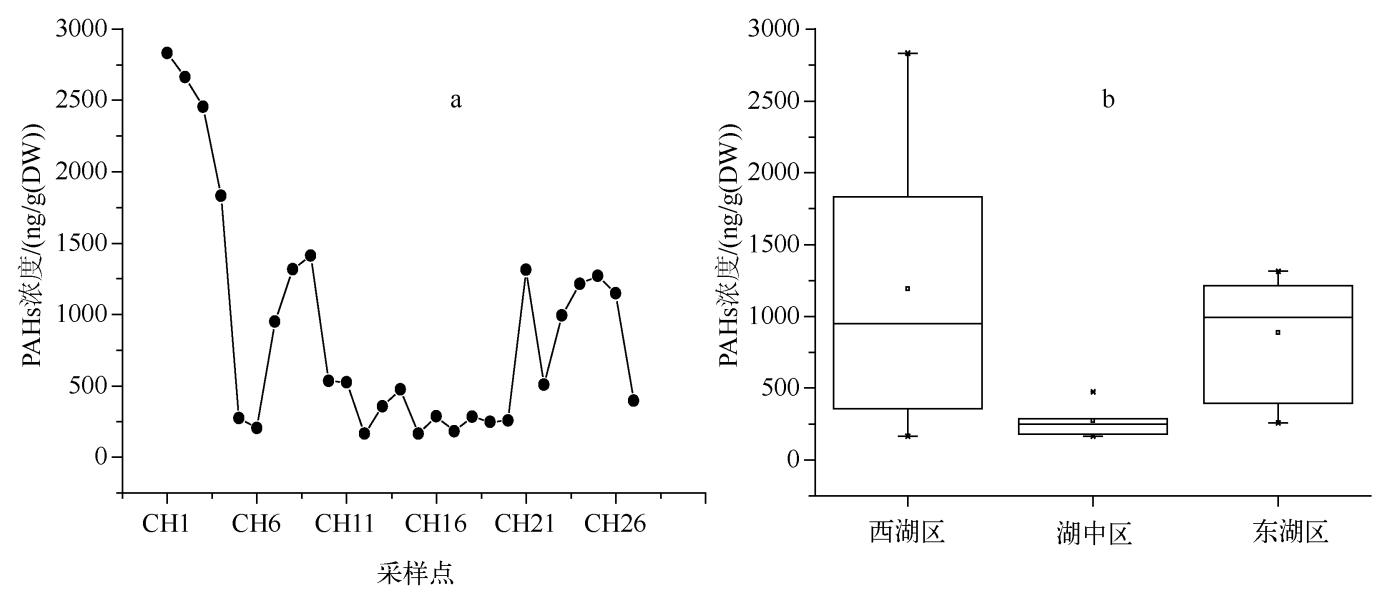

图 2 巢湖表层沉积物多环芳烃含量分布

Fig. 2 The concentration of PAHs in the surface sediment of Lake Chaohu

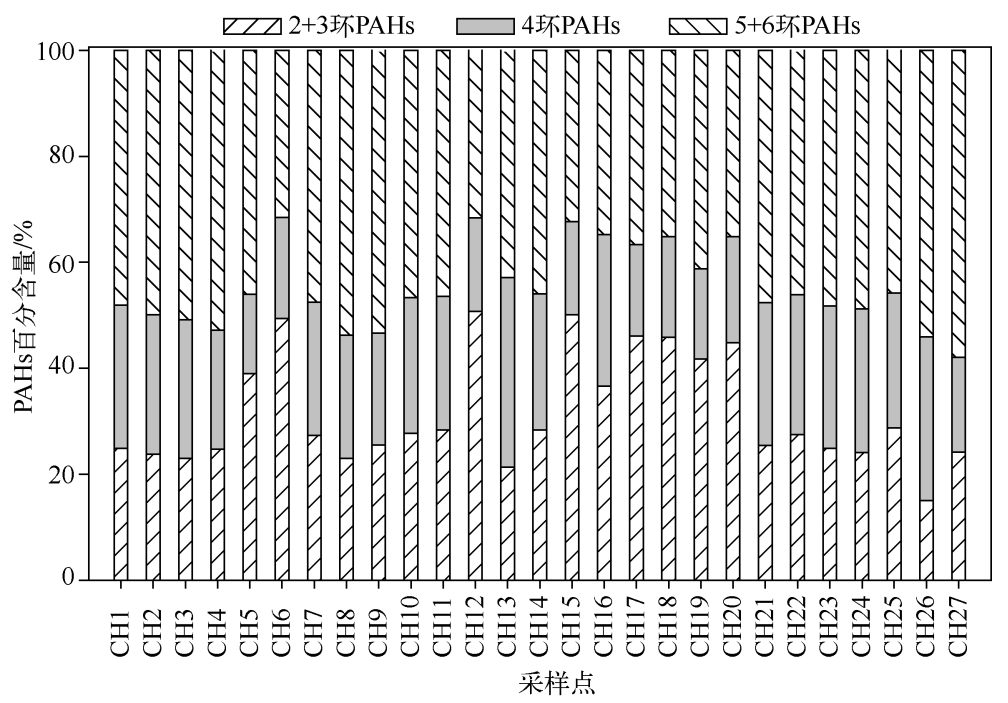

图 3 巢湖表层沉积物多环芳烃的组成特征

Fig. 3 The profiles of PAHs in the surface sediment of Lake Chaohu

随着距离增加, 沉积物中 PAHs 浓度先呈上升趋势, 在采样点 CH9 处达到最高点, 随后呈下降趋势 (图 4). 南 淝河河口处于河湖交界区域, Lisitsin ${ }^{[21]}$ 的研究表明由于 “边际过滤效应 (marginal filter)” 存在, 在交界区域, 90\% 93\% 的悬浮颗粒物都会因各种物理化学作用而沉淀, 而 PAHs 主要吸附在悬浮颗粒物上, 这直接导致 PAHs 浓度随着离岸距离的增加而减小, 另外水体的稀释作用在 PAHs 浓度变化中也起了重要的作用. 在由 派河河口向湖心的流动过程中, “边际过滤效应”、水体稀释的共同作用且受到南淝河严重污染的影响, 在初 始阶段南淝河污染的影响占到主导地位, 致 PAHs 浓度呈上升趋势, 随着离岸距离增加, 南泪河污染影响减 小, “边际过滤效应” 及水体稀释作用占主导, 这是导致 PAHs 浓度在这一阶段下降的主要原因. 巢湖污染底 泥的分布特征符合湖泊沉积学规律, 即表层沉积物属于严重污染层, 富含有机质. 但由于在派河河口进行了 生态底泥疏浚工程, 富含有机质的表层沉积物被清除, 故导致靠近派河河口的 CH5、CH6 多环芳烃浓度 较低. 

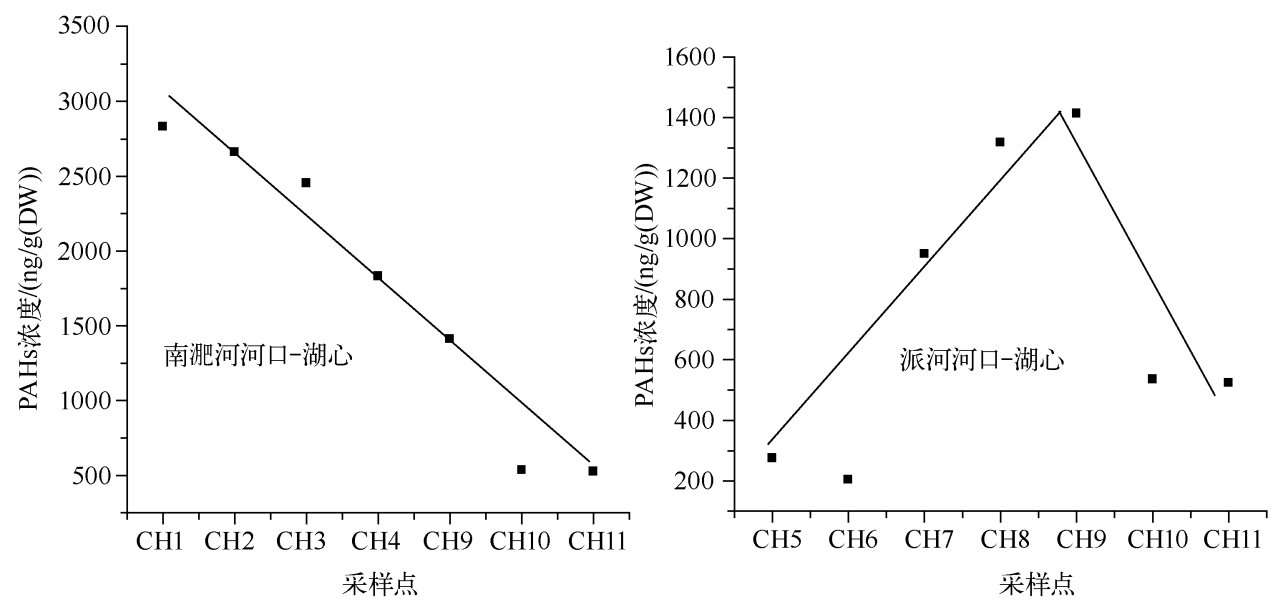

图 4 河口向湖心流向沉积物中多环芳烃含量变化趋势

Fig. 4 The trend of PAHs from river mouth to centre of lake in the surface sediment of Lake Chaohu

由于水溶性低, 辛醇水分配系数高, $\mathrm{PAHs}$ 等疏水性有 机污染物 $80 \%$ 以上分配富集在沉积物的有机质中 ${ }^{[9]}$. 沉积 物中由于富含有机质, 因此具有复杂的孔隙结构, 其孔隙 结构具有快速吸附的外表面及缓慢吸附的内表面, 因而极 易吸附 PAHs, 从而成了 PAHs 的蓄积库. 巢湖表层沉积物 中多环芳烃含量与总有机碳 ( Total Organic Carbon,TOC) 呈 显著的线性相关 (图 5 ), 具有高多环芳烃浓度的南淝河河 口有机质含量明显较高, 这说明沉积物中的有机质在控制 区域 PAHs 的归宿上起着一定的作用 (表 1 ). Karickhoff、 Wang 等的研究也指出 TOC 是沉积物中吸附 PAHs 的控制 因子 ${ }^{[22-23]}$.

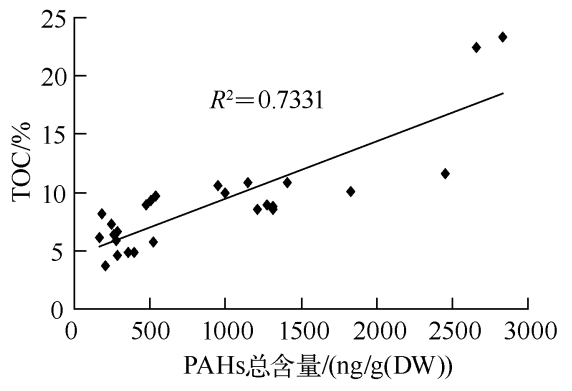

图 5 巢湖表层沉积物中 PAHs 与 TOC 的关系

Fig. 5 Correlation analysis between contents of PAHs and TOC in the surface sediment of Lake Chaohu

表 1 巢湖表层沉积物中 TOC 含量

Tab. 1 The concentration of TOC in the surface sediment of Lake Chaohu

\begin{tabular}{ccccccccccccccc}
\hline 点位 & CH1 & CH2 & CH3 & CH4 & CH5 & CH6 & CH7 & CH8 & CH9 & CH10 & CH11 & CH12 & CH13 & CH14 \\
\hline TOC/g & 23.41 & 22.35 & 11.60 & 10.10 & 5.83 & 3.64 & 10.63 & 8.82 & 10.89 & 9.71 & 5.70 & 6.15 & 4.82 & 8.97 \\
\hline \hline 点位 & CH15 & CH16 & CH17 & CH18 & CH19 & CH20 & CH21 & CH22 & CH23 & CH24 & CH25 & CH26 & CH27 & \\
\hline TOC/g & 6.13 & 4.63 & 8.13 & 6.67 & 7.30 & 6.38 & 8.59 & 9.32 & 10.00 & 8.59 & 8.97 & 10.80 & 4.89 & \\
\hline
\end{tabular}

\section{3 多环芳烃的来源}

多环芳烃主要来源于自然源和人为源. 自然源包括森林大火、火山喷发和生物合成等; 人为源主要包括 石油污染相关的 PAHs 及燃烧产生的 PAHs ${ }^{[24]}$. 目前用于甄别环境中 PAHs 污染源的方法主要有比值法、特 征化合物法、轮廓图法和多元统计法等 ${ }^{[25]}$, 其中比值法由于简单、易用而得到广泛应用. Ant/ $(A n t+P h e)$ 和 $\mathrm{BaA} /(\mathrm{BaA}+\mathrm{Chr})$ 值可用于区分 PAHs 的来源是燃烧还是原油污染. Ant $/(\mathrm{Ant}+\mathrm{Phe})<0.1$ 表明 PAHs 源自 原油污染, 而 Ant $/(\mathrm{Ant}+\mathrm{Phe})>0.1$ 则表明是燃烧源; $\mathrm{BaA} /(\mathrm{BaA}+\mathrm{Chr})<0.2$, 表示石油源, $\mathrm{BaA} /(\mathrm{BaA}+$ Chr $)>0.2$ 则表示燃烧源. 判断巢湖表层沉积物中 PAHs 污染来源的 Ant/ (Ant + Phe) 比值为 $0.13 \sim 0.33$ (图 6), 表明 PAHs 来源为木材、煤及焦炉等燃烧源; $\mathrm{BaA} /(\mathrm{BaA}+\mathrm{Chr})$ 值为 $0.40 \sim 0.64$, 表明 PAHs 以汽油、 木材及煤等燃烧为主要来源. 以上两种方法均表明巢湖表层沉积物中 PAHs 来源于燃烧. 巢湖周边地区交通 


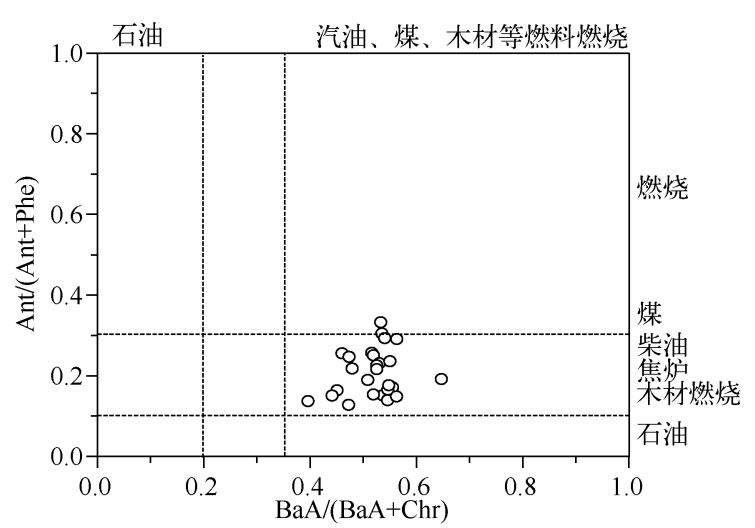

图 6 巢湖表层沉积物中 PAHs 的来源诊断

Fig. 6 Sources identification of PAHs in the surface sediment of Lake Chaohu

表 2 国内其他地区河流、湖泊及海湾 表层沉积物多环芳烃比较*

Tab. 2 Comparison of concentrations of PAHs in the surface sediment from various regions in China

\begin{tabular}{|c|c|c|c|}
\hline 采样点 & & $\begin{array}{l}\text { 多环芳烃 } \\
\text { 种类 }\end{array}$ & $\begin{array}{l}\text { PAHs 浓度/ } \\
(\mathrm{ng} / \mathrm{g}(\mathrm{DW}))\end{array}$ \\
\hline \multirow[t]{6}{*}{ 江河 } & 珠江三角洲 [29] & 25 & $294 \sim 1100(749)$ \\
\hline & 珠江河口 ${ }^{[8]}$ & 16 & $191 \sim 622(321)$ \\
\hline & 黄浦江 ${ }^{[30]}$ & 16 & $244 \sim 4348(1600)$ \\
\hline & 第二松花江中下游 ${ }^{[31}$ ] & 5 & $447 \sim 20331$ ( 3789$)$ \\
\hline & 黄河干流 ${ }^{[32]}$ & 16 & $2250 \sim 2324(2287)$ \\
\hline & 淮河 (淮南-蚌埠段) ${ }^{[33]}$ & 16 & $5 \sim 78(20)$ \\
\hline \multirow[t]{5}{*}{ 湖泊 } & 江苏云龙湖 ${ }^{[13]}$ & 15 & $5 \sim 19(13)$ \\
\hline & 白洋淀 ${ }^{[26]}$ & 16 & $101 \sim 1495(353)$ \\
\hline & 天目湖 [34] & 16 & $288 \sim 714(459)$ \\
\hline & 南四湖 ${ }^{[35]}$ & 16 & $229 \sim 609(442)$ \\
\hline & 安徽巢湖[本研究] & 14 & $116.0 \sim 2832.2(899)$ \\
\hline \multirow[t]{4}{*}{ 海湾 } & 渤海湾近岸 [10] & 10 & $25 \sim 35(28)$ \\
\hline & 南海近岸带 ${ }^{8]}$ & 16 & $75 \sim 219(135)$ \\
\hline & 台州湾海域 [11] & 15 & $85 \sim 168(139)$ \\
\hline & 香港维多利亚港 ${ }^{[36]}$ & 8 & $700 \sim 26100(5277)$ \\
\hline
\end{tabular}

*括号内为平均值.
网络由国道、高速路、市/区级公路等 组成, 交通便利, 污染较严重. 目前使 用汽油为燃料的机动车数量最多, 使 用柴油和天然气为燃料的相对较少, 致使沉积物中可以检测出明显的汽油 燃烧源; 另外城市中汽车燃烧产物和 家庭燃烧产物中较高浓度的 PAHs 随 着雨水的冲刷进人水体, 最终进人到 沉积物中, 成为巢湖表层沉积物中 $\mathrm{PAHs}$ 的另一个人为来源; 随着巢湖周 边区域旅游业的开发, 使用柴油或者 汽油为燃料的游船增多, 加上繁忙的 水上运输, 汽油等化石燃料的不完全 燃烧最终也成为 PAHs 的一个主要 来源.

多环芳烃环数相对丰度可以反映 来自热解或石油类污染 ${ }^{[26]}$. 有研究显 示, 高分子量的 4 环和 5 6 环 PAHs 主要来自燃烧源, 而低分子量的 $2 \sim 3$ 环 PAHs 则主要来自石油类物质的输 ${ }^{[27-28]}$. 巢湖表层沉积物中以 $5 \sim 6$ 环 $\mathrm{PAHs}$ 为主, 占总量的 32\% 58\%, 表 明燃烧源 (如汽车尾气、煤及木材燃 烧) 是该区域沉积物中 PAHs 的主要 来源. 这与比值法所得出的结论是一 致的.

\section{4 巢湖表层沉积物中多环芳烃污染 水平}

巢湖表层沉积物中 PAHs 浓度与 珠江三角洲相近, 处于同一水平; 与 珠江河口、淮河、江苏云龙湖、白洋 淀、渤海湾近岸、南海近岸带和台州 湾海域相比, 高出 2 69 倍; 而经济 发达地区的河流、河口及近海海岸, 如香港维多利亚港、黄河干流、第二 松花江中下游及黄浦江沉积物中

PAHs 的浓度则高出巢湖表层沉积物 $2 \sim 6$ 倍 (表 2). 综上可知, 巢湖表层沉积物中 PAHs 污染程度与国内 其它河流、河口及近海海岸相比处于中等污染水平.

\section{5 巢湖表层沉积物中多环芳烃的生态风险评估}

低分子量 (2 3 环) PAHs 具有显著急性毒性, 而某些高分子量 PAHs 则有潜在的致癌作用 ${ }^{[37]}$. Long 等 ${ }^{[38]}$ 提出了沉积物中 PAHs 潜在生态风险低值 (Effects Range Low, ERL) 和中值 (Effects Range Median, $E R M)$. 当污染物含量大于 $E R M$, 则产生严重的生态风险; 当污染物含量在二者之间, 则具有潜在的生态风 险; 当污染物含量小于 $E R L$, 则不产生负面生态风险. 大部分采样点沉积物中多环芳烃含量均低于对应化合 物的 $E R L$ 值, 仅南淝河河口沉积物中的范、葱、二苯并 $[\mathrm{a}, \mathrm{h}$ ] 葱、芴、菲高于相应的 $E R L$, 但小于相应的 $E R M$ 
(表 3), 可见目前巢湖表层沉积物中多环芳烃生 态风险较小, 但是随着城市快速发展、汽车使用数 量的大幅度增加, 加上 PAHs 不易被分解、在环境 中长时间存在特性, 其潜在的生态风险仍不能被 忽视.

\section{4 结论}

14 种优先控制 PAHs 在巢湖表层沉积物各采 样点均有检出, 具有高致癌性的 $5 \sim 6$ 环 PAHs 占 较大比例. 巢湖表层沉积物 PAHs 与有机质含量 呈显著的线性相关, 主要来源于汽油、木材及煤的 燃烧. 与国内其它地区水体比较得出, 巢湖表层沉 积物中 PAHs 污染程度处于中等污染水平, 但除 南汁河河口外, 巢湖其他表层沉积物 PAHs 生态 风险较小.

\section{5 参考文献}

表 3 巢湖表层沉积物多环芳烃生态风险评估

$$
(\mathrm{ng} / \mathrm{g}(\mathrm{DW}))
$$

Tab. 3 Toxicity evaluation of PAHs for the surface sediment of Lake Chaohu

\begin{tabular}{lcrc}
\hline PAHs & $E R L$ & $E R M$ & 本研究 \\
\hline 范 & 16 & 500 & $1.1 \sim 101.3$ \\
葱 & 85 & 1100 & $3.0 \sim 129.3$ \\
苯并 $[\mathrm{a}]$ 葱 & 261 & 1600 & $5.8 \sim 259.8$ \\
苯并芘 & 430 & 1600 & $4.3 \sim 331.2$ \\
屈 & 384 & 2800 & $5.8 \sim 226.9$ \\
二苯并 $[\mathrm{a}, \mathrm{h}]$ 葸 & 63 & 260 & $2.2 \sim 123.8$ \\
荣葱 & 600 & 5100 & $0.7 \sim 45.8$ \\
芴 & 19 & 540 & $9.2 \sim 129.2$ \\
萫 & 160 & 2100 & $11.4 \sim 83.1$ \\
菲 & 240 & 1500 & $18.5 \sim 261.2$ \\
芘 & 665 & 2600 & $15.0 \sim 232.1$ \\
\hline
\end{tabular}

[1] 朱 樱, 吴文婧, 王军军等. 小白洋淀水一沉积物系统多环芳烃的分布、来源与生态风险. 湖泊科学, 2009,21 (5): $637-646$.

[2] 欧冬妮,刘 敏,许世远等. 基于多参数指标的长江口滨岸多环芳烃来源辨析. 地理学报,2008,63(5):535-543.

[ 3 ] Lauenstein GG, Kimbrough KL. Chemical contamination of the Hudsone-Raritan Estuary as a result of the attack on the World Trade Center: Analysis of polycyclic aromatic hydrocarbons and polychlorinated biphenyls in mussels and sediment. Marine Pollution Bulletin, 2007, 54: 284-294.

[ 4 ] Yang Z, Feng J, Niu J et al. Release of polycyclic aromatic hydrocarbons from Yangtze River sediment cores during periods of simulated resuspension. Environmental Pollution, 2008, 155 : 366-374.

[ 5 ] Latimer JS, Davis WR, Keith DJ. Mobilization of PAHs and PCBs from in-place contaminated marine sediments during simulated resuspension events. Estuarine Coastal and Shelf Science, 1999, 49 : 577-595.

[ 6 ] Schneider A, Porter E, Baker A. Polychlorinated biphenyl release from resuspended Hudson River sediment. Environmental Science \& Technology, 2007, 41: 1097-1103.

[ 7 ] 许士奋,蒋 新,王连生等. 长江和辽河沉积物中的多环芳烃类污染物. 中国环境科学, 2000,20(2):128-131.

[8] 罗孝俊, 陈社军, 麦碧涃等. 珠江及南海北部海域表层沉积物中多环芳烃分布及来源. 环境科学, 2005,26(4): 129-134.

[9] 陈卓敏, 高效江, 宋祖光等. 杭州湾潮滩表层沉积物中多环芳烃的分布及来源. 中国环境科学, 2006, 26 (2): $233-237$.

[10] 林秀梅, 刘文新, 陈江麟等. 渤海表层沉积物中多环芳烃的分布与生态风险评价. 环境科学学报, 2005,25 (1): $70-75$.

［11］江锦花. 台州湾海域表层沉积物中多环芳烃的浓度水平、富集规律及来源. 海洋通报,2007,26(4):85-90.

[12] 袁旭音, 李阿梅, 王 禹等. 太湖表层沉积物中的多环芳烃及其毒性评估. 河海大学学报: 自然科学版, 2004,32 (6) :607-610.

[13] 丁文文,韦 萍. 徐州市云龙湖沉积物中多环芳烃的污染研究. 安徽农业科学, 2007,35(34):11197-11198.

[14] 李如忠. 巢湖水环境生态修复探讨. 合肥工业大学学报:社会科学版,2002,16(5):130-133.

[15］王 睿. 巢湖流域水环境质量评价与水质预测模型研究[学位论文].合肥:合肥工业大学,2009.

[16] 纪 岚,杨立武,李 菁等. 南淝河水污染现状与可持续发展对策研究. 安徽大学学报: 自然科学版,2006,30(4): $91-94$

[17］何开丽.巢湖富营养化现状与治理对策. 环境保护,2004,4:22-24.

[18］周怀东, 赵 健, 陆 瑾. 白洋淀湿地表层沉积物多环芳烃的分布、来源及生态风险评价. 生态毒理学报, 2008,3 
(3) :291-299.

[19] 邹爱红. 巢湖西半湖水体中有机污染物监测及污染现状的研究 [ 学位论文]. 合肥: 合肥工业大学, 2009.

[20] 张生根. 基于 GIS 的巢湖流域考古信息系统研究与建设. 测绘与空间地理信息, 2007,30(4):28-32.

[21] Lisitsin AP. Marginal filter of the oceans. Oceanologia, 1994, 34(5) : 735-747.

[22] Karickhoff SW, Brown DS, Scott TA. Sorption of hydrophobic pollutants on natural sediments. Water Research, 1979, 13: $241-248$.

[23] Wang XC, Zhang YX, Chen RF. Distribution and partitioning of polycyclic aromatic hydrocarbons (PAHs) in different size fractions in sediments from Boston Harbor, United States. Marine Pollution Bulletin, 2001, 42 : 1139-1149.

[24] 包 贞,潘志彦. 环境中的多环芳烃的分布及降解. 浙江工业大学学报,2003,31(5):528-533.

[25] 程远梅, 祝凌燕, 田胜艳等. 海河及渤海表层沉积物中多环芳烃的分布与来源. 环境科学学报, 2009,29(11): 2420-2426.

[26] 胡国成, 郭建阳, 罗孝俊等. 白洋淀表层沉积物中多环芳烃的含量、分布、来源及生态风险评价. 环境科学研究, $2009,22(3): 321-326$.

[27] Soclo HH, Ewald M. Origin of polycyclic aromatic hydrocarbons ( PAHs) in coastal marine sediments: case studies in Cotonou(Benin) and Aquitaine(France) areas. Marine Pollution Bulletin, 1999, 40: 387-396.

[28] 张枝焕, 卢 另, 贺光秀等. 北京地区表层土壤中多环芳烃的分布特征及污染源分析. 生态环境学报, 2011, 20(4): $668-675$.

[29] 罗孝俊, 陈社军, 麦碧涃等. 珠江三角洲地区水体表层沉积物中多环芳烃的来源、迁移及生态风险评价. 生态毒理 学报,2006,1(1):17-24.

[30] 胡雄星,周亚康,韩中豪等. 黄浦江表层沉积物中多环芳烃的分布特征及来源. 环境化学,2005,24(6):703-707.

[31] 陆继龙,蔡 波,郝立波等. 第二松花江中下游河段底泥中多环芳烃的初步研究. 岩矿测试, 2007,26(4):325-327.

[32] 罗雪梅, 刘昌明, 何孟常. 黄河沉积物中多环芳烃的分布特征及来源分析. 环境科学研究, 2005,18(2):48-50.

[33] 王 庆, 丁 毅, 李玉成等. 淮河淮南一蚌埠段沉积物中的多环芳烃污染性状研究. 宿州学院学报, 2007,22(6): $103-106$.

[34] 舒卫先, 李世杰. 江苏天目湖表层沉积物中多环芳烃污染特征与来源. 长江流域资源与环境, 2009,18(1):27-32.

[35] 史双昕, 杨永亮, 石 否等. 南四湖表层沉积物中多环芳烃的分布及其来源. 青岛大学学报:工程技术版,2005,20 (4) :95-99.

[36] Hong GH, Xu L, Zhang L et al. Environmental fate and chemistry of organic pollutions in the sediments of Xiamen and Victoria Harbors. Marine Pollution Bulletin, 1995, 31 : 229-236.

[37] 赵 健, 周怀东, 陆 瑾等. 河北王快水库沉积物多环芳烃的分布、来源及生态风险评价. 湖泊科学, 2009,21 (5): $647-653$.

[38] Long ER, Macdonald DD, Smith SL et al. Incidence of adverse biological effects within ranges of chemical concentrations in marine and estuary sediments. Environmental Management, 1995, 19: 81-97. 